\title{
Job Satisfaction of Agricultural Extension Functionaries for Dissemination of Information in District Baramulla of Jammu \& Kashmir
}

\author{
K.Manobharathi $^{{ }^{*}}$, Shijaatt Hussain Bhat ${ }^{2}$, Kethavath Naresh ${ }^{2}$ and Farhana $^{2}$ \\ ${ }^{1}$ Agriculture Extension \& Communication, Sher-e-Kashmir University of Agricultural \\ Sciences and Technology, Faculty of Agriculture and Regional Research Station, \\ WaduraSopore, Jammu and Kashmir, India-193201 \\ ${ }^{2}$ Division of Agriculture Extension \& Communication, SKUAST-Kashmir, India \\ *Corresponding author
}

\section{A B S T R A C T}

\begin{tabular}{l} 
K e y w o r d s \\
Agricultural \\
Extension \\
Functionaries, \\
Technological \\
satisfaction, \\
Administrative \\
satisfaction, Service \\
and supply \\
satisfaction, Pay \\
satisfaction, Job \\
satisfaction \\
\hline Article Info \\
\hline $\begin{array}{l}\text { Accepted: } \\
22 \text { June } 2020 \\
\text { Available Online: } \\
\text { 10 July } 2020\end{array}$ \\
\hline
\end{tabular}

Keywords

Agricultural

Extension

Functionaries, satisfaction, Administrative and supply satisfaction, Pay satisfaction, Job satisfaction

\section{Introduction}

Agriculture is an important sector of the Indian economy, accounting for $15.87 \%$ of the nation's GDP, about $12.8 \%$ of its exports, about $58 \%$ of the Indian population still relies on agriculture as its principal source of income (Anonymous 2018 a). The need and
The present study regarding the Job satisfaction of Agricultural Extension Functionaries (AEFs) for dissemination of information was carried out in three purposively selected Sub-Divisional Agricultural Offices namely Baramulla, Sopore and Rohama in district Baramulla of Jammu \& Kashmir. Among the Sub-Divisional Extension functionaries, all Subject Matter Specialists (SMS's), Agricultural Extension Officers (AEO's), Agricultural Assistants Inputs (AAI's), Junior Agricultural Extension Officers (JAEO's) and Agricultural Extension Assistants (AEA's) were taken for collecting the primary data with the help of a well-structured interview schedule. The study reveals that under each aspects of satisfaction, majority (53.96 \%) of AEFs were having medium level of technological satisfaction; majority $(47.48 \%)$ of AEFs were having medium level of administrative satisfaction; majority $(43.89 \%)$ of AEFs were having medium level of service and supply satisfaction; majority (74.82 \%) of AEFs were having medium level of pay satisfaction. Finally, regarding overall satisfaction, majority $(48.20 \%)$ of AEFs were having medium level of job satisfaction. 
through various State and Central Sponsored Schemes to incentivize farmers for adopting latest technology to enhance the production and income (Anonymous, 2019 a). Agriculture Extension Functionaries are responsible for the transfer of technology, the task of extension personnel is to translate these technologies and advisories from research system to farmers into an understandable form so that farmers could understand easily and extension personnel also provides a technological feedback to research system to improve a particular technology. Job satisfaction of Agricultural Extension Functionaries is of greater importance for their effective implementation of Extension activities.

Job satisfaction is defined as the extent to which an employee feels self-motivated, contented and satisfied with his/her job. Job satisfaction will be attained only when an employee feels he or she is having job stability, career growth and a comfortable work life balance. This implies that the employee is having satisfaction at job as the work meets the expectations of the individual (Anonymous 2011a).

\section{Materials and Methods}

The research design followed in the present study was ex-post-facto design, since the phenomenon has already occurred. Kashmir valley consists of 10 districts and the present study was conducted in Baramulla district of Jammu and Kashmir which was selected purposively because it is the largest district in entire Kashmir valley both with reference to population and area. In district Baramulla, totally six Sub Divisional Agricultural Offices namely Baramulla, Pattan, Sopore, Rohama, Uri and Tangmarg are present. Out of which three Sub-Divisional Agricultural Offices namely Baramulla, Sopore and Rohama were selected purposively on the basis of maximum area under Agricultural practices. Among the Sub-Divisional Extension functionaries, all Subject Matter Specialists (SMSs), Agricultural Extension Officers (AEOs), Agricultural Assistants Inputs (AAIs), Junior Agricultural Extension Officers (JAEOs) and Agricultural Extension Assistants (AEAs) were selected in all the three Sub-Divisional Agricultural Offices. A total of 139 Agricultural Extension Functionaries from these three Sub-Divisions were selected as Agricultural Extension Functionaries (AEFs) for the study.

\section{Measurement of Variables}

To measure the level of job satisfaction of Agricultural Extension Functionaries, a list of twenty one questions were prepared by discussing with experts from Agriculture Extension and by referring to review of literature. Each question was framed in a statement form to obtain the response from Agricultural Extension Functionaries (AEFs). Twenty one items/statements were administered to Agricultural Extension Functionaries (AEFs) along with five point continuum representing 'very much satisfied, 'satisfied', 'partially satisfied', 'dissatisfied' and 'very much dissatisfied with assigned score of 5,4,3,2 and 1 respectively for positive statements and vice versa for negative statements.

The satisfaction score of an AEF were calculated by adding up the scores obtained by an individual on all items/statements. The satisfaction score of this scale ranges from a minimum of 21 to a maximum of 105 . Higher score on the scale indicates that the Agricultural Extension Functionaries (AEFs) have higher level of satisfaction towards their job.

The mean and standard deviation of the job satisfaction were 74.88 and 9.95 respectively. 
Initially, based on the maximum score (100) obtained and minimum score (55) obtained, Agricultural Extension Functionaries (AEFs) were categorized into six job satisfaction categories viz., very low, low, low medium, high medium, high and very high. Exclusive method was followed while categorizing the level of job satisfaction.

\section{Results and Discussion}

\section{Job Satisfaction of Agricultural Extension Functionaries for Dissemination of Information in District Baramulla of Jammu \& Kashmir under each aspect}

From the Table-1 and Figure-1, it is clear that, under the technological aspects, majority $(27.34 \%)$ of the Agricultural Extension Functionaries (AEFs) belonged to low medium category of satisfaction followed by 26.62 per cent of AEFs belonged to high medium category of satisfaction, 25.18 per cent of AEFs belonged to high category of satisfaction, 10.07 per cent of AEFs belonged to very high category of satisfaction, 8.63 per cent of AEFs belonged to low category of satisfaction and 2.16 per cent of AEFs belonged to very low category of satisfaction.

In other words it can be concluded that, under the technological aspects, majority (53.96\%) of the Agricultural Extension Functionaries (AEFs) were having medium level of satisfaction followed by 35.25 per cent of AEFs were having high level of satisfaction and 10.79 per cent of AEFs were having low level of satisfaction with mean and standard deviation of 14.39and 2.54respectively.

The possible reason for majority of AEFs were in medium satisfaction on technological aspects is because AEFs were partially satisfied with facilities for conducting demonstrations, systematic trainings, exposure visits and support from lower staffs.
From the Table-1 and Figure-2, it is clear that, under the administrative aspects, majority $(38.13 \%)$ of the Agricultural Extension Functionaries (AEFs) belonged to high medium category of satisfaction followed by 34.53 per cent of AEFs belonged to high category of satisfaction, 12.23 per cent of AEFs belonged to very high category of satisfaction, 9.35 per cent of AEFs belonged to low medium category of satisfaction, 4.32 per cent of AEFs belonged to low category of satisfaction and 1.44 per cent of AEFs belonged to very low category of satisfaction.

In other words it can be concluded that, under the administrative aspects, majority (47.48\%) of the Agricultural Extension Functionaries (AEFs) were having medium level of satisfaction followed by 46.76 per cent of AEFs were having high level of satisfaction and 5.76 per cent of AEFs were having low level of satisfaction with mean and standard deviation of 17.28 and 3.11respectively.

The possible reason for majority of AEFs were in medium satisfaction on administrative aspects is because AEFs were partially satisfied with employee promotional decisions, benefits from the organization, sensible rules and regulations, procedure and policies, relationship among the staffs and coordination among the different departments.

From the Table-1 and Figure-3, it is clear that, under the service and supply aspects, majority (26.62 \%) of the Agricultural Extension Functionaries (AEFs) belonged to low medium category of satisfaction followed by 25.18 per cent of AEFs belonged to high category of satisfaction, 17.27 per cent of AEFs belonged to high medium category of satisfaction, 15.11 per cent of AEFs belonged to low category of satisfaction, 8.63 per cent of AEFs belonged to very high category of satisfaction and 7.19 per cent of AEFs belonged to very low category of satisfaction. 
Table.1 Job satisfaction level of Agricultural Extension Functionaries under each aspect

\begin{tabular}{|c|c|c|c|c|c|c|}
\hline \multicolumn{2}{|c|}{ Aspects of Job satisfaction } & Scores & Frequency & Percentage (\%) & Mean & $\begin{array}{l}\text { Standard } \\
\text { Deviation }\end{array}$ \\
\hline \multicolumn{7}{|c|}{ (a). Technological aspects } \\
\hline \multirow[t]{2}{*}{ Low } & Very low & $(8-10)$ & 03 & 2.16 & \multirow{7}{*}{14.39} & \multirow{7}{*}{2.54} \\
\hline & Low & $(10-12)$ & 12 & 8.63 & & \\
\hline \multirow[t]{2}{*}{ Medium } & Low medium & $(12-14)$ & 38 & 27.34 & & \\
\hline & High medium & $(14-16)$ & 37 & 26.62 & & \\
\hline \multirow[t]{2}{*}{ High } & High & $(16-18)$ & 35 & 25.18 & & \\
\hline & Very high & $\begin{array}{c}\text { (18 \& } \\
\text { above) }\end{array}$ & 14 & 10.07 & & \\
\hline \multicolumn{3}{|c|}{ Total } & 139 & 100 & & \\
\hline \multicolumn{7}{|c|}{ (b). Administrative aspects } \\
\hline \multirow[t]{2}{*}{ Low } & Very low & $(6-9)$ & 02 & 1.44 & \multirow{7}{*}{17.28} & \multirow{7}{*}{3.11} \\
\hline & Low & $(9-12)$ & 06 & 4.32 & & \\
\hline \multirow[t]{2}{*}{ Medium } & Low medium & $(12-15)$ & 13 & 9.35 & & \\
\hline & High medium & $(15-18)$ & 53 & 38.13 & & \\
\hline \multirow[t]{2}{*}{ High } & High & $(18-21)$ & 48 & 34.53 & & \\
\hline & Very high & $\begin{array}{c}(21 \& \\
\text { above })\end{array}$ & 17 & 12.23 & & \\
\hline \multicolumn{3}{|c|}{ Total } & 139 & 100 & & \\
\hline \multicolumn{7}{|c|}{ (c). Service \& Supply aspects } \\
\hline \multirow[t]{2}{*}{ Low } & Very low & $(16-19)$ & 10 & 7.19 & \multirow{7}{*}{25.01} & \multirow{7}{*}{4.39} \\
\hline & Low & $(19-22)$ & 21 & 15.11 & & \\
\hline \multirow[t]{2}{*}{ Medium } & Low medium & $(22-25)$ & 37 & 26.62 & & \\
\hline & High medium & $(25-28)$ & 24 & 17.27 & & \\
\hline \multirow[t]{2}{*}{ High } & High & $(28-31)$ & 35 & 25.18 & & \\
\hline & Very high & $\begin{array}{c}(31 \& \\
\text { above })\end{array}$ & 12 & 8.63 & & \\
\hline \multicolumn{3}{|c|}{ Total } & 139 & 100 & & \\
\hline \multicolumn{7}{|c|}{ (d). Pay satisfaction } \\
\hline \multirow[t]{2}{*}{ Low } & Very low & $(10-13)$ & 03 & 2.16 & \multirow{7}{*}{18.19} & \multirow{7}{*}{2.78} \\
\hline & Low & $(13-16)$ & 12 & 8.63 & & \\
\hline \multirow[t]{2}{*}{ Medium } & Low medium & $(16-19)$ & 66 & 47.48 & & \\
\hline & High medium & $(19-22)$ & 38 & 27.34 & & \\
\hline \multirow[t]{2}{*}{ High } & High & $(22-25)$ & 19 & 13.67 & & \\
\hline & Very high & $\begin{array}{c}(25 \& \\
\text { above })\end{array}$ & 01 & 0.72 & & \\
\hline \multicolumn{3}{|c|}{ Total } & 139 & 100 & & \\
\hline
\end{tabular}


Table.2 Overall Job satisfaction level of Agricultural Extension Functionaries

\begin{tabular}{|c|c|c|c|c|c|}
\hline \multicolumn{2}{|c|}{ Level of Job Satisfaction } & \multirow{2}{*}{$\begin{array}{c}\text { Frequency } \\
15\end{array}$} & \multirow{2}{*}{$\begin{array}{c}\text { Percentage (\%) } \\
10.79\end{array}$} & \multirow[t]{2}{*}{ Mean } & $\begin{array}{l}\text { Standard } \\
\text { Deviation }\end{array}$ \\
\hline \multirow[t]{2}{*}{ Low } & Very low(55-63) & & & & \multirow{7}{*}{9.95} \\
\hline & Low $(63-71)$ & 38 & 27.34 & \multirow{6}{*}{74.88} & \\
\hline \multirow[t]{2}{*}{ Medium } & Low medium (71-79) & 38 & 27.34 & & \\
\hline & High medium (79-87) & 29 & 20.86 & & \\
\hline \multirow[t]{2}{*}{ High } & High $(87-95)$ & 15 & 10.79 & & \\
\hline & $\begin{array}{l}\text { Very high } \\
\text { (95\& above) }\end{array}$ & 04 & 2.88 & & \\
\hline \multicolumn{2}{|r|}{ Total } & 139 & 100 & & \\
\hline
\end{tabular}

Fig.1 Distribution of AEFs according to their Technological satisfaction

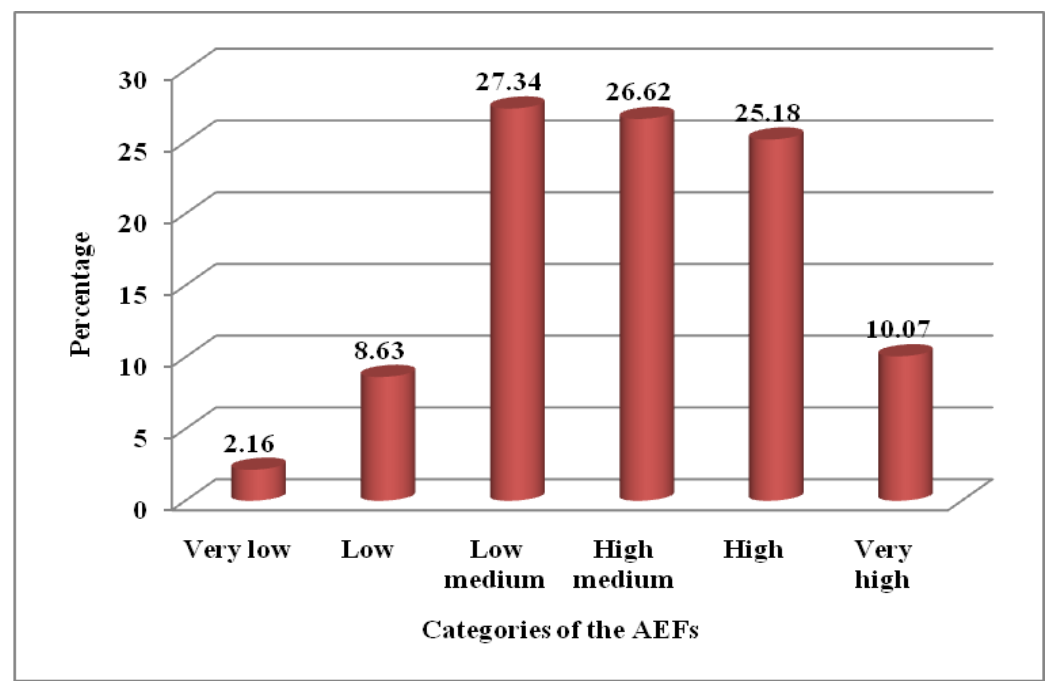

Fig.2 Distribution of AEFs according to their Administrative satisfaction

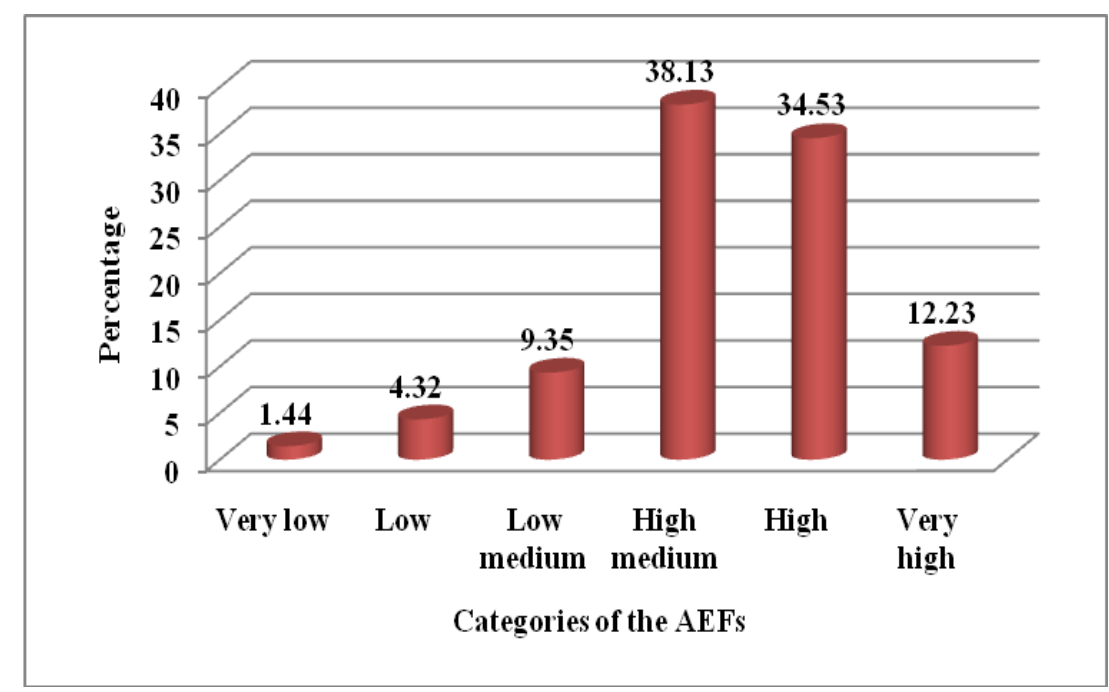


Fig.3 Distribution of AEFs according to their Service and supply satisfaction

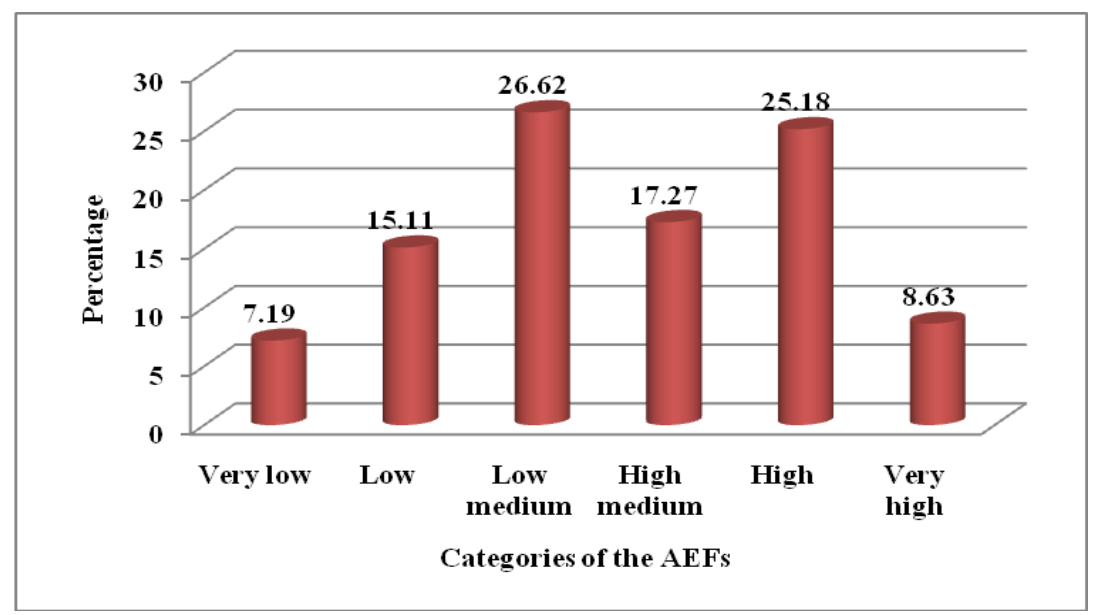

Fig.4 Distribution of AEFs according to their Pay satisfaction

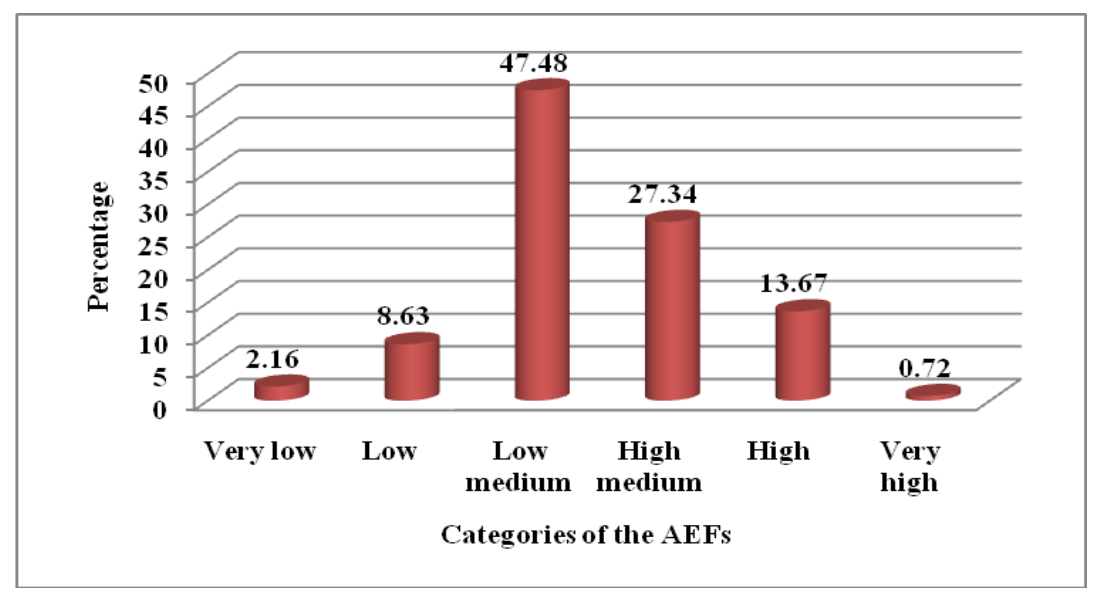

Fig.5 Distribution of AEFs according to their overall Job satisfaction

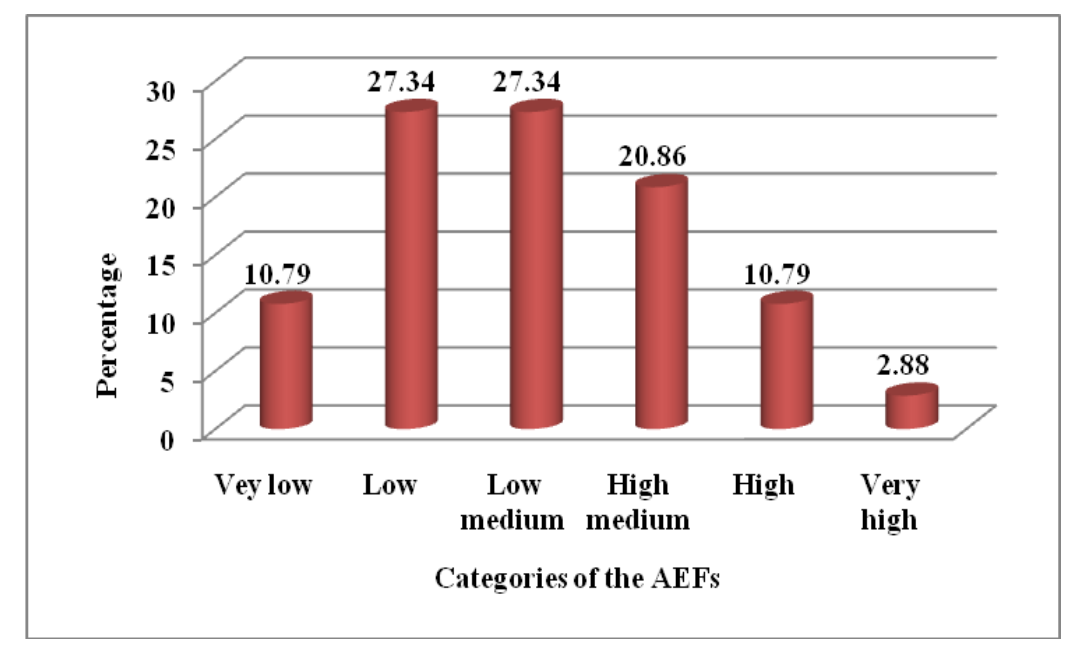


In other words it can be concluded that, under the service and supply aspects, majority (43.89 \%) of the Agricultural Extension Functionaries (AEFs) were having medium level of satisfaction followed by 33.81 per cent of AEFs having high level of satisfaction and 22.30 per cent of AEFs were having low level of satisfaction with mean and standard deviation of 25.01 and 4.39respectively.

The possible reason for majority of AEFs were in medium satisfaction on service and supply aspects is because AEFs were partially satisfied with timely inputs and arrangement, timely teaching aid availability, timely credit to the farmers, post-harvest management of the farmers produce and relationship with superior.

From the Table-1 and Figure-4, it is clear that, under the aspect of pay satisfaction, majority $(47.48 \%)$ of the Agricultural Extension Functionaries (AEFs) belonged to low medium category of satisfaction followed by 27.34 per cent of AEFs belonged to high medium category of satisfaction, 13.67 per cent of AEFs belonged to high category of satisfaction, 8.63 per cent of AEFs belonged to low category of satisfaction, 2.16 per cent of AEFs belonged to very low category of satisfaction and 0.72 per cent of AEFs belonged to very high category of satisfaction.

In other words it can be concluded that, under the aspect of pay satisfaction, majority (74.82 $\%)$ of the Agricultural Extension Functionaries (AEFs) were having medium level of satisfaction followed by 14.39 per cent of AEFs were having high level of satisfaction and 10.79 per cent of AEFs were having low level of satisfaction with mean and standard deviation of 18.19 and 2.78respectively.

The possible reasons for majority of AEFs were in medium satisfaction on pay aspects is because AEFs were partially satisfied with pay by considering skills, efforts and qualification, timely incentives and timebound promotions.

Overall Job satisfaction level of Agricultural Extension Functionaries for Dissemination of Information in District Baramulla of Jammu and Kashmir

From the Table-2and Figure-5, it is clear that, 27.34 per cent of the Agricultural Extension Functionaries (AEFs) belonged to low medium category and low category of job satisfaction, 20.86 per cent of AEFs belonged to high medium category, 10.79 per cent of AEFs belonged to high category and very low category and 2.88 per cent of AEFs belonged to very high category of job satisfaction.

In other words it can be concluded that, majority $(48.20 \%)$ of the Agricultural Extension Functionaries (AEFs) were having medium level of job satisfaction, whereas 38.13 per cent and 13.67 per cent of the AEFs were having low and high level of job satisfaction respectively with mean and standard deviation of 74.88 and 9.95 respectively.

The probable reason for most of AEFs were in the medium job satisfaction level is because that mostly the AEFs job satisfaction is based on several factors such as income/salary providence on time, administrative assistance, technological assistance, service and supply assistance etc., from the organization. Nowadays, AEFs in the Department of Agriculture were getting better salary on time as it is a Government organization but AEFs were not highly satisfied and they are only partially satisfied with other technological, administrative and supply aspects. This finding is line with 
findings of Manjula (2000) and Maity et al., (2007).

In conclusion under the technological aspects of satisfaction, majority $(27.34 \%)$ of the Agricultural Extension Functionaries (AEFs) belonged to low medium category of satisfaction. In other words it can be concluded that, under the technological aspects, majority $(53.96 \%)$ of the Agricultural Extension Functionaries (AEFs) were having medium level of satisfaction.

Under the administrative aspects of satisfaction, majority $(38.13 \%)$ of the Agricultural Extension Functionaries (AEFs) belonged to high medium category of satisfaction. In other words it can be concluded that, under the administrative aspects,majority (47.48\%) of the Agricultural Extension Functionaries (AEFs) were having medium level of satisfaction.

Under the service and supply aspects of satisfaction, majority $(26.62 \%)$ of the Agricultural Extension Functionaries (AEFs) belonged to low medium category of satisfaction. In other words it can be concluded that, under the service and supply aspects, majority (43.89 \%) of the Agricultural Extension Functionaries (AEFs) were having medium level of satisfaction.

Under the aspect of pay satisfaction, majority $(47.48 \%)$ of the Agricultural Extension Functionaries (AEFs) belonged to low medium category of satisfaction. In other words it can be concluded that, under the aspect of pay satisfaction, majority (74.82\%) of the Agricultural Extension Functionaries (AEFs) were having medium level of satisfaction.

Under overall job satisfaction, 27.34 per cent of the Agricultural Extension Functionaries (AEFs) belonged to low medium category of job satisfaction and also 27.34 per cent of AEFs belonged to low category of job satisfaction. In other words it can be concluded that, majority $(48.20 \%)$ of the Agricultural Extension Functionaries (AEFs) were having medium level of job satisfaction.

\section{References}

Anonymous, 2011a. Definition: Job Satisfaction,http://www.mbaskool.com.

Anonymous, 2018a. Economy of IndiaWikipedia, http://en.m.wikipedia.org

Anonymous, 2019a.Agricultural Production Department, Jammu \& Kashmir, (http://diragrikmr.nic.in/ )

Manjula N. 2000. A study on job perception, job performance and job satisfaction of Agricultural Assistant Officers (Field Workers) in Karnataka, International Journal of Development Research, 4(8):1643-1650.

Maity, M., Malik, B. S., Mandal, M. K., Gautam, P. K. and Roy Choudhary, A., 2007. Determinants of job satisfaction among livestock development assistants of West Bengal, India. Livestock Research and Rural Development. 19(6): 86-89.

\section{How to cite this article:}

Manobharathi, K., ShijaattHussain Bhat, Kethavath Naresh and Farhana. 2020. Job Satisfaction of Agricultural Extension Functionaries for Dissemination of Information in District Baramulla of Jammu \& Kashmir. Int.J.Curr.Microbiol.App.Sci. 9(07): 3789-3796.

doi: https://doi.org/10.20546/ijcmas.2020.907.443 